\title{
A NOVEL CONTROL STRATEGY FOR ENHANCEMENT OF POWER QUALITY USING FUZZY LOGIC
}

\author{
Sakshi Bangia ${ }^{1}$, P.R.Sharma ${ }^{2}$, Maneesha Garg $^{3}$ \\ ${ }^{1}$ Department of Electrical Engineering, YMCAUST Faridabad, India \\ sakshi.bangia@gmail.com \\ ${ }^{2}$ Chairman, Department of Electrical Engineering, YMCAUST Faridabad, India \\ prsharma1966 @gmail.com \\ ${ }^{3}$ Department Humanities and Applied Science, YMCAUST Faridabad, India \\ garg_maneesha@yahoo.com
}

\begin{abstract}
This paper deals with simulation of shunt active filters using fuzzy logic to improve the power quality and reduction in the transient time of capacitor voltage, when there is change in load. Shunt active power filter can compensate current harmonics by injecting equal-but-opposite harmonic compensating current.A new control strategy is proposed which is based on energy of the capacitor, dc-link voltage to reduce the transient time of capacitor The Fuzzy logic controller is used to predict the reference current values and the firing pulses were generated using hysteresis current controller. The system was modelled and simulated using MATLAB/SIMULINK power system toolbox. Analysis and comparison of the proposed strategy in terms of the response time of capacitor and power quality, with Proportional-Integral (PI) controller and with fuzzy logic controller are the key features of the paper.
\end{abstract}

\section{KEYWORDS}

Shunt Active Filter, Total HarmonicDistortion, Voltage Source Inverter, Fuzzy Logic, Power Quality, transient time

\section{INTRODUCTION}

Power system harmonics are defined as sinusoidal voltage and currents at frequencies that are integer multiples of the main generated (or fundamental) frequency. They constitute the major distorting components of the mains voltage and load current waveforms. The proliferation of microelectronics processors in a wide range of equipments, from home VCRs and digital clocks to automated industrial assembly lines and hospital diagnostics systems has increased the vulnerability of such equipment to power quality problems [1]. Additional causes of power system voltage unbalances can be due to asymmetrical transformer winding impedances, open star and open delta transformer banks and asymmetrical transmission line impedances [2].

A flexible and versatile solution to voltage quality problems is offered by active power filters. This method uses sophisticated electronics and power section IGBTs to inject equal and opposite harmonics onto the power system to cancel those generated by other equipment. These filters monitor the nonlinear currents demanded from nonlinear loads and electronically generate currents that match and cancel the destructive harmonic currents. Active filters are inherently non-resonating and are easily connected in parallel with system loads. Active filters have the

DOI : $10.5121 / \mathrm{ijics.2012.2405}$ 
ability to adjust the amplitude of the synthesized ac voltage of the inverters by means of PWM by control of dc link voltage, thus drawing either leading or lagging power from the supply. The objective is to force the source current to be sinusoidal and in phase with the source voltage to have reduced Total Harmonic Distortion (THD) and unitary power factor at the source line.

For power quality control, a Fuzzy Logic Controller (FLC) Model gives comparatively better harmonic reduction than the conventional PI Controllers . [6,7] FLC presents a good tool to deal with complicated, non indefinite and time-variant systems The advantages of fuzzy control are that it does not require accurate mathematical model, can work with imprecise inputs, can handle nonlinearity and are more robust than other conventional nonlinear .The main objective of this study is to improve the power quality by developing a control algorithm for shunt active filter using fuzzy logic controller to eliminate the harmonics in power systems. A new energy based fuzzy logic control strategy is introduced to reduce the transient time of the capacitor voltage whenever there is sudden increase/decrease of load take place. A hysteresis controller based current controller was used and the simulation results are presented followed by the conclusion.

\section{PRINCIPLE OF OPERATION}

The power stage of a shunt APF needs to pass bidirectional current and it is typically composed of a full bridge or half bridge with an energy storage capacitor at the DC side. The APF system connected in parallel with the load can cancel the harmonic/reactive components in the line current $\left(i_{\mathrm{s}}\right)$ so that the current flow into and from the power line is sinusoidal and in phase with the power line voltage. In other words, the compensating current $\left(i_{f}\right)$ is injected into the line to force the line current $\left(i_{s}\right)$ approach to sinusoid and unity-power-factor can be achieved by APF system. The currents of the APF system can be expressed as

$\mathrm{i}_{\mathrm{s}}=\mathrm{i}_{\mathrm{f}+} \mathrm{i}_{1}$

Where $i_{1}$ is the nonlinear load current.

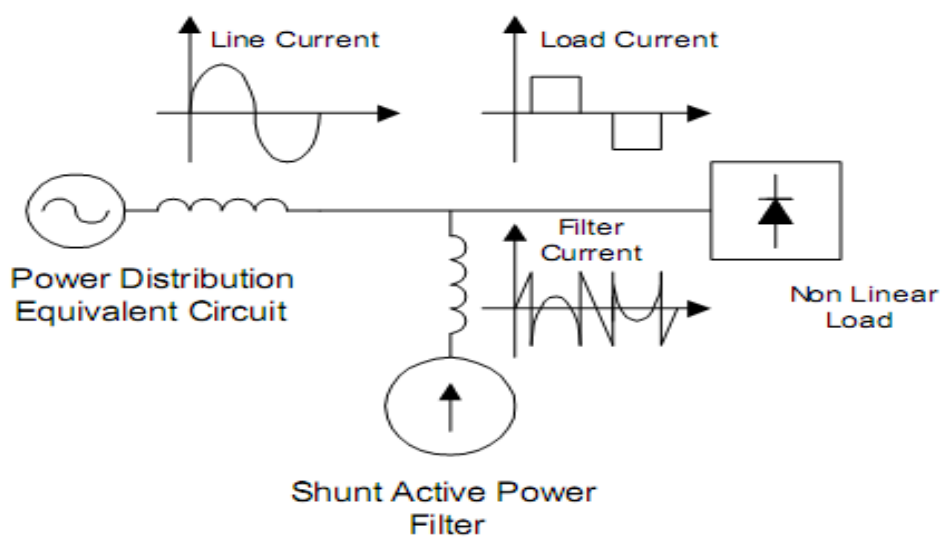

Figure 1. Characteristics of shunt active filter

The VSI injects an appropriate current into the system to compensate for the undesired components of load current that are responsible for low power factor. The harmonic compensation performance of an active filter depends mainly on the technique used to compute the reference current, the design of inverter and the control method used to inject the desired 
compensation current into the line. The DC side of the converter is connected to a capacitor, whose voltage can be raised or lowered by controlling the converter

\subsection{Synchronous Reference Frame Control Strategy}

The block diagram of the synchronous reference frame controller is shown in Fig 3.The basic structure of SRF methods consists of direct (d-q) and inverse (d-q) park transformations, which allow the evaluation of a specific harmonic component of the input signals. The reference frame transformation is formulated from a three-phase a-b-c stationery system to the two-phase direct axis (d)-quadratic, (q) - rotating coordinate system. In a-b-c stationary axes are fixed on the same plane and separated from each other by 120 degree. These three phase space vectors stationary coordinates are easily transformed into two axis d-q rotating reference frame.with the sine and cosine functions calculated using a PLL (Phase Locked Loop). The SRF is ability to compensate harmonics and reactive-power component from the distortion load currents [8-10].

With this transformation, the fundamental positive sequence components are transformed into dc quantities in $\mathrm{d}$ and $\mathrm{q}$ axes, which can easily be extracted by low-pass filter (LPF). All harmonic components are transformed into ac quantities with a fundamental frequency shift.[11]

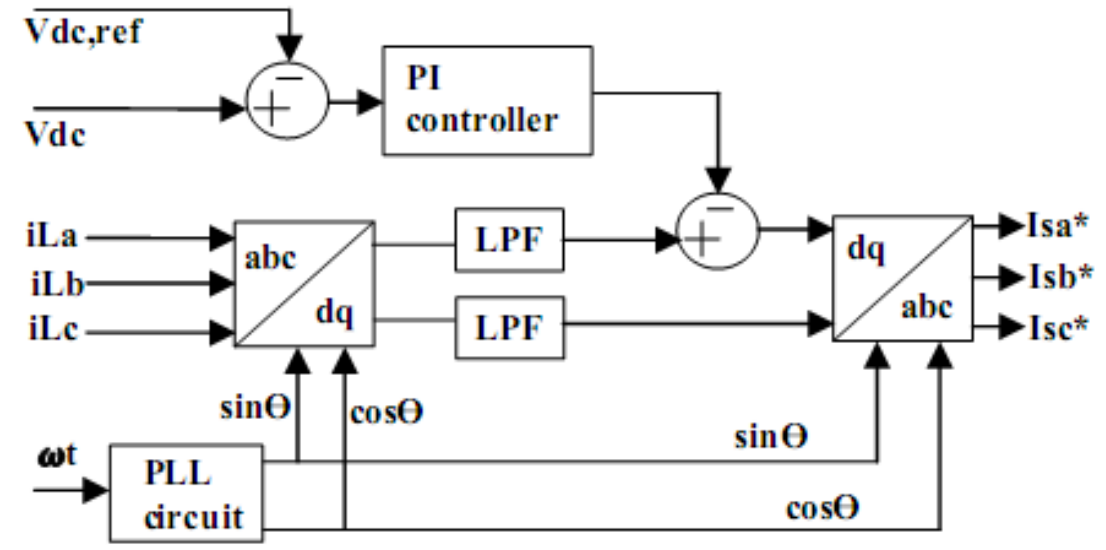

Figure 2. Synchronous reference frame control

$\mathrm{i}_{\mathrm{ld}}=\mathrm{i}_{\mathrm{ldd}}+\mathrm{i}_{\mathrm{ldc}}, \mathrm{ilq}=\mathrm{i}_{\mathrm{lqd}}+\mathrm{i}_{\mathrm{lqc}}$

Reference current components in the d-axis and q-axis are expressed in

$\mathrm{i}^{*}{ }_{\mathrm{fd}}=\mathrm{i}_{\mathrm{ldc}}, \mathrm{i}^{*}{ }_{\mathrm{fq}}=\mathrm{i}_{\mathrm{lqc}}$

In this situation, system currents are

$\mathrm{i}_{\mathrm{sd}}=\mathrm{i}_{\mathrm{ldd}}, \mathrm{i}_{\mathrm{sq}}=\mathrm{i}_{\text {lqd }}$

If correction of power factor considered, reference current components and system currents are expressed are as follows

$i^{*}{ }_{\mathrm{fd}}=\mathrm{i}_{\mathrm{ldc}}, \mathrm{i}_{\mathrm{fq}}=\mathrm{i}_{\mathrm{lqc}}$

$\mathrm{i}_{\mathrm{sd}}=\mathrm{i}_{\text {ldd }}, \mathrm{i}_{\mathrm{sq}}=0$ 
Reference currents are then inversely transformed into a-b-c reference frame. The output compensatory currents of the shunt compensator are obtained by a Hysteresis current control.

\subsection{Energy based Fuzzy Logic Control of DC Capacitor}

When the APF is compensating the harmonic and reactive power components, the dc capacitor voltage $V_{d c}$ varies. Hence $V_{d c}$ is also sensed and regulated at a reference value $V_{\text {dcref }}$ in order to establish a self-sufficient energy at the bus .DC side capacitor serves two main purposes (i)the it maintains a dc voltage with small ripple in steady state and (ii) serves as an energy storage element to supply real power difference between load and source during transient period.

Instead of PI controller an Energy based control of $V_{\mathrm{dc}}$ is presented the paper which is based on the ability of capacitor to regulate the voltage under transient condition. The energy required by the dc-link capacitor to charge from actual voltage to the reference value can be computed as

$\mathrm{W}_{\mathrm{dC}}=\mathrm{C}_{\mathrm{dc}}\left(\mathrm{V}_{\mathrm{dc} \text { ref }}^{2}-\mathrm{v}_{\mathrm{dc}}^{2}\right)$

Now the total de power required by the de link capacitor is computed as follows:

$\mathrm{P}_{\mathrm{dc}}=\mathrm{K}_{\mathrm{pe}}\left(\mathrm{V}_{\mathrm{dcref}}^{2}-\mathrm{v}_{\mathrm{dc}}^{2}\right)+\mathrm{K}_{\mathrm{ie}}\left(\mathrm{V}_{\mathrm{dcref}}^{2}-\mathrm{v}_{\mathrm{dc}}^{2}\right)$

Design of proportional and integral gain in the energy based controller can be determined by by assuming $\mathrm{V}_{\mathrm{dc}}$ ref $+\mathrm{V}_{\mathrm{dc}}$ is equal to $2 \mathrm{~V}_{\mathrm{dc} \text { ref. [3] }}$

In our application, the fuzzy control algorithm is implemented to control the DC side capacitor voltage based on processing of DC voltage error $\mathrm{e}(\mathrm{t})$ and its variation $\Delta \mathrm{e}(\mathrm{t})$ in order to improve the dynamic of APF and reduce the total harmonic ratio of the source current. The input variables are given by

$\mathrm{e}(\mathrm{t})=\mathrm{V}_{\mathrm{dcref}}^{2}-\mathrm{v}_{\mathrm{dc}}^{2}$

$\Delta \mathrm{e}(\mathrm{t})=\mathrm{e}(\mathrm{t})-\mathrm{e}(\mathrm{t}-1)$

A fuzzy controller consists of fourth stages: fuzzification, knowledge base, fuzzification, inference mechanisms, and defuzzification. The structure of the fuzzy logic current controller consists of two inputs and one output. The inputs are namely error e $(t)$, and change in error $\Delta \mathrm{e}(\mathrm{t}) \mathrm{The}$ determination of the membership functions depends on the designer's experiences and expert knowledge. A triangular membership function has the advantages of simplicity and easy implementation, and is adopted in this application $[4,5]$. Table 1 shows rules for the input and output linguistic variables used.

Various inference mechanisms have been developed to defuzzify fuzzy rules. In this paper, we apply the max-min inference method to get an implied fuzzy set of turning rules. The imprecise fuzzy control action generated by the inference engine must be transformed into a precise control action in a real application. The centroid method is used to defuzzify the implied fuzzy control variables. 
Table 1. Fuzzy Rules

\begin{tabular}{|c|c|c|c|}
\hline $\begin{array}{c}\text { change of } \\
\text { error } \\
\text { error }\end{array}$ & SN & S & SP \\
\hline SN & PS & Z & SN \\
\hline S & Z & PS & Z \\
\hline SP & SN & Z & PS \\
\hline
\end{tabular}

\subsection{Switching Strategy of controller}

The Hystersis current controllers of the three phases are designed to operate independently. Each current controller determines the switching signals to the inverter.The error signal refernce and actual source current are calculated and compared within a small hystersis band $\left(h_{b}\right)$.The switching logic for phase A is formulated as below;

If $i_{\mathrm{fa}}<\left(i_{\mathrm{fa}}-h_{\mathrm{b}}\right)$ upper switch of VSC TURNED is OFF and lower switch is ON If $\mathrm{i}_{\mathrm{fa}}<\left(\mathrm{i}_{\mathrm{fa}}+\mathrm{hb}\right)$ upper switch of VSC is turned ON and lower switch is OFF

In the same fashion, the switching of phase $\mathrm{B}$ and $\mathrm{C}$ devices are derived.

\section{IMPLEMENTATION OF FUZZIFIED BASED TECHNIQUE}

The shunt active power was simulated using a model built in the Simulink environment of Matlab. The parameters of the system are as follows:

$\mathrm{Vs}=415 \mathrm{~V}(\mathrm{~L}-\mathrm{L}), \mathrm{fs}=50 \mathrm{~Hz}, \mathrm{Rs}=0.19 \Omega, \mathrm{Ls}=2 \mathrm{e}-3 \mathrm{H}, \mathrm{Rf}=0.2 \Omega, \mathrm{Lf}=3.1 \mathrm{e}-6 \mathrm{H}$, and $\mathrm{V}_{\text {dcref }}$ $=550 \mathrm{~V}$.

Loads: (i) Linear: phase $a=25 \Omega$; Phase $b=44 \Omega$ and $81 \mathrm{mH}$; Phase $\mathrm{c}=44 \Omega$ and $81 \mathrm{mH}$

(ii) Non linear: Three phase full bridge rectifier drawing $5 \mathrm{~A}$

The ac load consists of a three phase unbalanced load and a non linear load of bridge rectifier (three phase) feeding a highly inductive R-L load.

The performance of active filter is demonstrated for reduction in the transient time and power factor correction with harmonic reduction. The model is analyzed under switching of load from full load to half load at 0.4 s to 0.8 s.

\subsection{Performance of Dc Capacitor Voltage using PI and Proposed Scheme}

The shunt connected active filter works in such a way that when capacitor voltage increases above the reference value due to sudden decrease in load, the capacitor absorbs surplus power from the source. Based on the values of PI controller gains, the capacitor voltage controller will be brought back to the reference value after a few cycles. Similarly, when the load is switched back to the full load at instant $0.8 \mathrm{~s}$, the dc capacitor supplies power to the load momentarily and, hence, the dc voltage falls below the reference value. The dc capacitor supplies power to the load momentarily. 
Fig 3 shows the transient performance of the Energy based voltage controllers using PI controller. Clearly time taken by the energy based method is from $0.4 \mathrm{~s}$ to $0.412 \mathrm{~s}$.

In comparison less time is taken by the capacitor voltage when fuzzy logic controller is used. It has been clearly notified from figure 4 showing the transient performance of the Energy based voltage controllers using fuzzy controller. Time taken by the energy based method is from $0.4 \mathrm{~s}$ to $0.405 \mathrm{~s}$

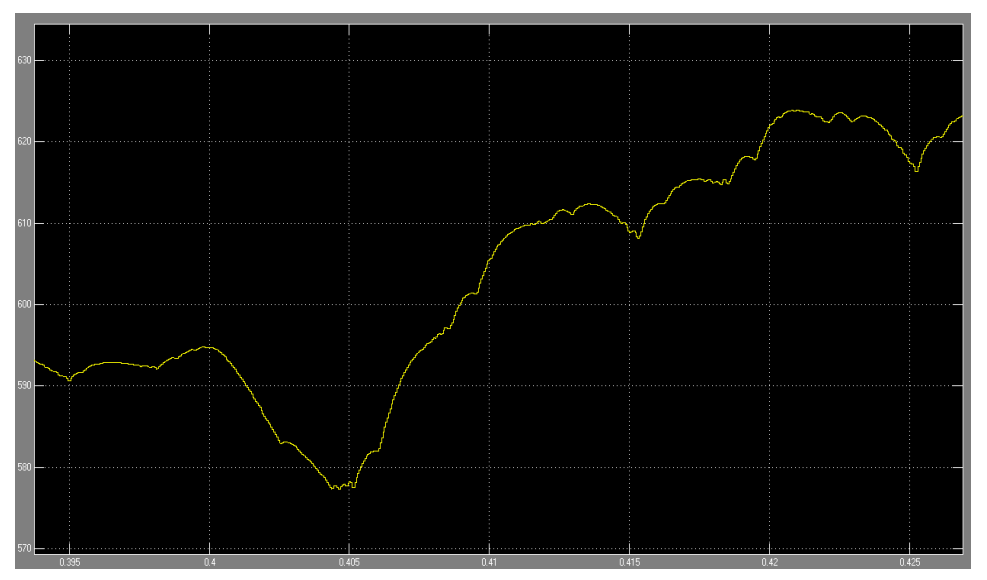

Figure 3 Transient time of $\mathrm{V}_{\mathrm{dc}}$ using Energy Based method and PI controller

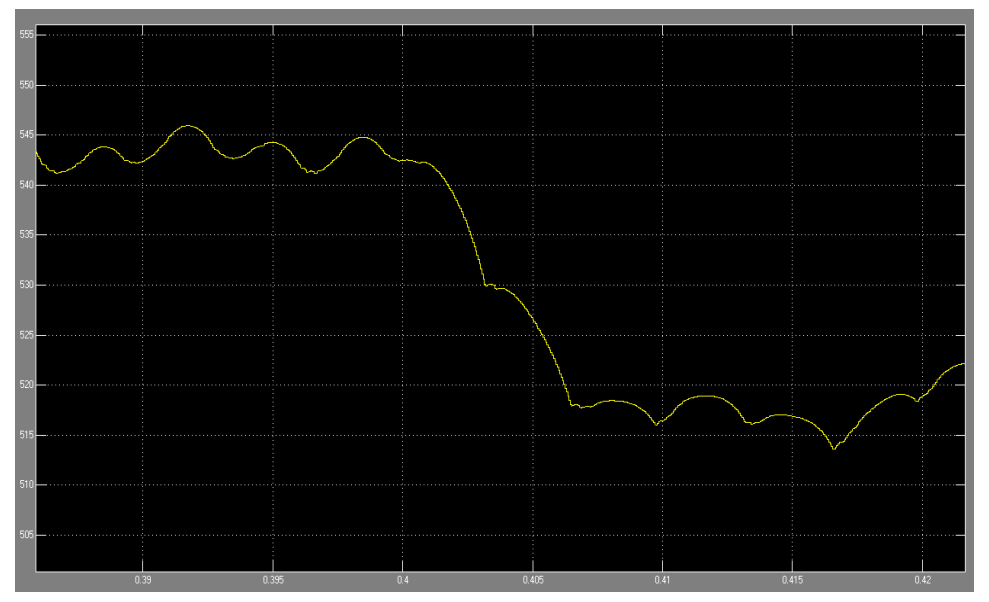

Figure 4 Transient time of $\mathrm{V}_{\mathrm{dc}}$ using Energy Based method and fuzzy controller

\subsection{Performance of Active Filter using Fuzzy Logic}

Figure 5 illustrate the performance of Active Filter using Fuzzy logic controller for power factor correction. Results verify that source current and source voltage are clearly in phase with each other confirming power factor correction.

The performance of active filter with fuzzy controller is shown in Fig 6.The supply voltage; supply current, load current, capacitor voltage and compensating currents are demonstrated, clearly indicates that though load current is unbalanced and distorted whereas source current are sinusoidal, capacitor link voltage is maintained at constant value. 
International Journal of Instrumentation and Control Systems (IJICS) Vol.2, No.4, October 2012

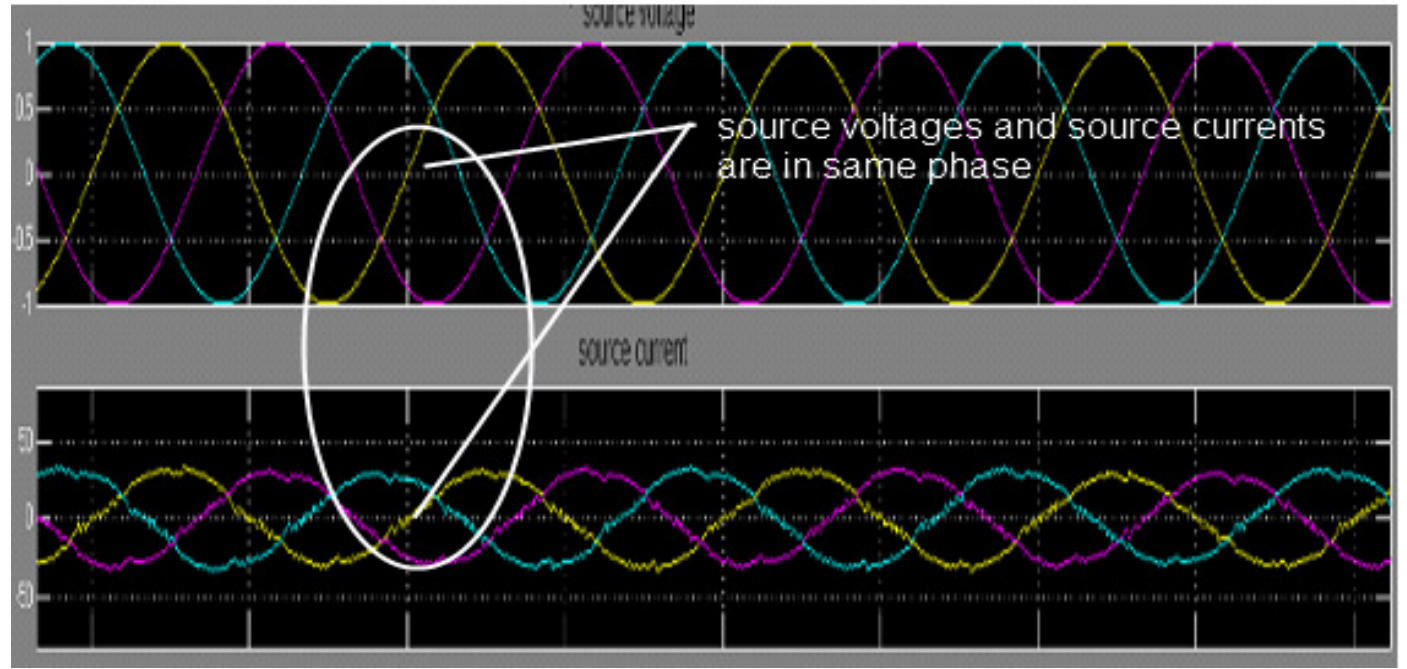

Figure 5 source voltage and source current for power factor correction

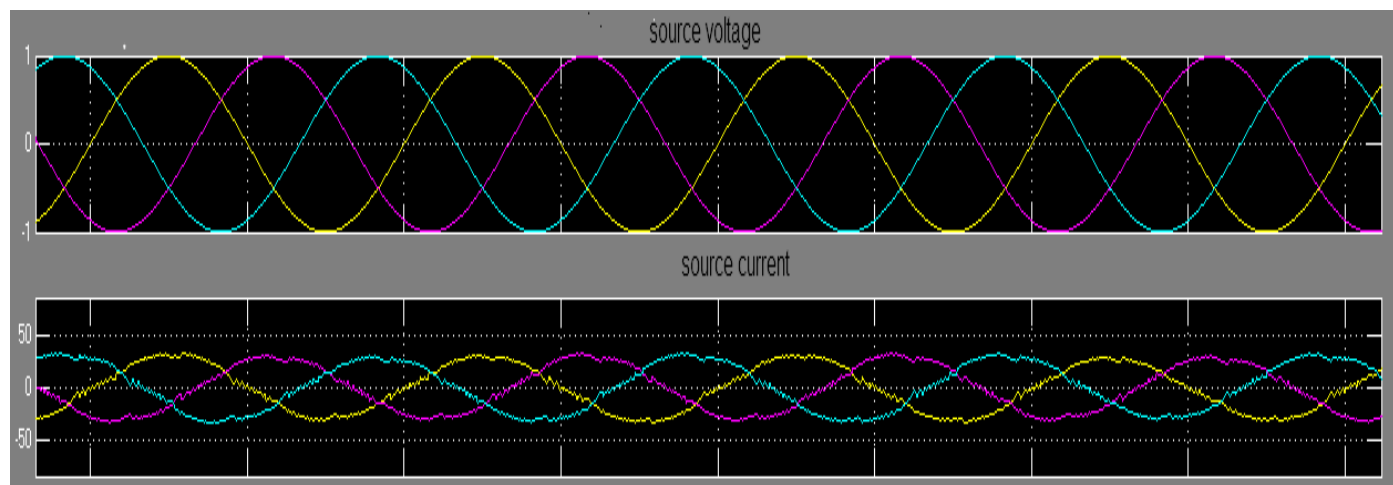

load current
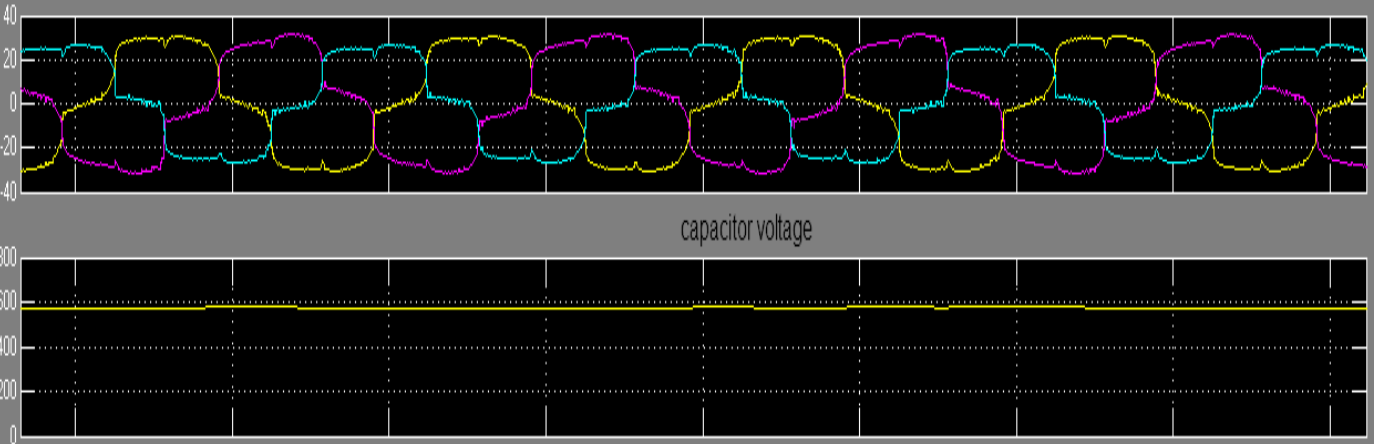

compensating current

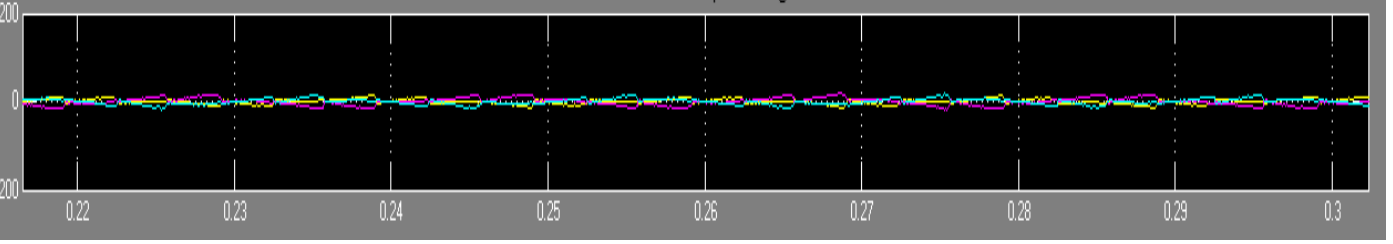

Figure 6 source voltage, source current, load current, capacitor voltage and compensating currents 
Total Harmonic Distortion (THD) is measured with the source current using PowerGui in simulink.The FFT analysis shown in figure 7 indicates that the active filter brings the THD of the source from to $3.62 \%$ that is less than 5\% which is in compliance with IEEE 519-1992 and IEC 61000-3 standards for harmonics under non-linear and/or unbalanced load conditions.

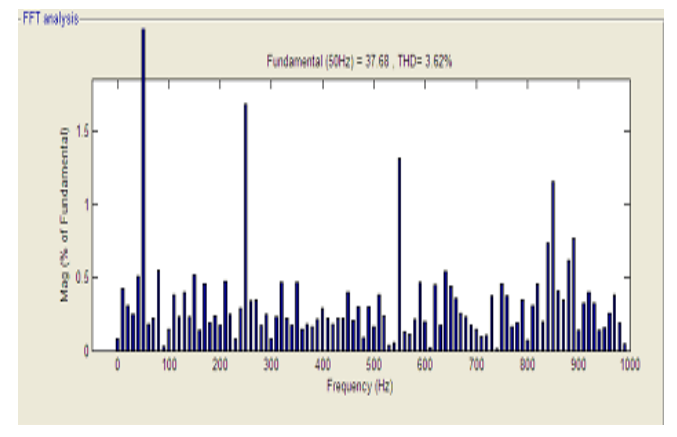

Fig 7 FFT analysis of source current

\section{Conclusions}

This paper has validated a simple control approach with a shunt active power filter based on the method of synchronous reference frame method, used to identify the reference currents. Simulations results show that an active power filter is a high performance power electronics converter and can operate in different modes: harmonics elimination, power factor correction, load unbalance compensation. A fuzzy logic based current controller strategy is used to regulate the filter current to ensure harmonic free supply current. For sudden change in load , a Fuzzy Logic Controller (FLC) Model provides better reduction in the response time of dc voltage than the conventional PI Controllers. The FLC based controller has quick response and more robust than other conventional nonlinear controllers.

\section{REFERENCES}

[1] K. Eichert, T. Mangold, M. Weinhold, "Power Quality Issues and their Solution", in VII Seminariode Electrónica de Potencia, Valparaíso, Chile, Abril 1999.

[2] Akagi, H., Kanazawa, Y. \& Nabae, A., "Instantaneous reactive power compensators comprising switching devices without energy storage components", IEEE Transactions on Industry Applications, Vol. 20, No. 3, pp. 625 - 630, May / June, 1984.

[3] Sakshi bangia ,P.R.Sharma ,Maneesha garg,"Energy Based Control Strategy for Reduction in the Response time of Dstatcom", Wseas Transaction on power system, issue 4 volume 6 oct 2011

[4] S. S. Min, K. C. Lee, J. W. Song, and K. B. Cho, "A Fuzzy current controller for field-orientated controlled induction machine by fuzzy rule," in Proceedings of the IEEE Power Electronics Specialists Conference (PESC), 1992, pp. 265-270.

[5] J. M. Mendel, "Fuzzy logic systems for engineering: a tutorial," in Proceedings of the IEEE, Vol. 83, 1995, pp. 345-375.

[6] Ghasemi, A., S.S. Mortazavi and R. Kianinezhad,"Fuzzy logic controlled adaptive active power filter for harmonics minimization and reactive power compensation under fast load variation. WSEAS Trans. Power Syst., 3: 300-309.

[7] Kerrouche, S. and F. Karim, 2009. Three-phase active power filter based on fuzzy logic controller. Int. J. Sci. Tech. Automatic Control Comput. Eng., 3: 942-955

[8] Alberto Pigazo, Victor M. Moreno and Emilio J. Estebanez "A Recursive Park Transformation to Improve the Performance of Synchronous Reference Frame Controllers in Shunt Active Power Filters" IEEE Trans on Power Electronics, Vol.24, No.9, sept-2009. 
International Journal of Instrumentation and Control Systems (IJICS) Vol.2, No.4, October 2012

[9] S.Bhattacharya, T.M.Frank, D.M.Divan and B.Banerjee "Parallel active filter system implementation and design issuses for utility interface of adjusTable speed drive systems" IEEE Conference, pp. 1032-1039, 1996

[10] Mariusz Malinowkski, K.Gopakumar, Jose Rodriguez and Marcelo A.Perez "A Survey on Cascaded Multilevel Inverters" IEEE Trans on IndustrialElectronics, Vol.57, No7, July-2010.

[11] Deepika Masand,,Gayantri Agnihotri,"Control strategies for distribution static compensator for power quality improvement “,IETE journal,July 2009.

[12] M.Isabel,M.Montero,E.R.Cadaval,F.B.Gonzalez "Comparison of Control Strategies for Shunt Active Power Filters in Three-Phase Four-Wire Systems" IEEE Trans. on Power Elects, Vol. 22,No.1,2007.

[13] O.Vodyakho.T.Kim,"Shunt active filter based on three-level inverter for 3-phase four-wire systems",IET Power Electronics,Vol.2,No.3, pp. 216-226, 2006.

[14] W.Diyun,C.Yanbo,K.W.Cheng,"Design and Performance of a Shunt Active Power Filter for ThreePhase Four-Wire Systems",IEEE Conf. ICPESA 2009.

[15] P.Salmer,S.P.Litran,"A Control Statergy for Hybrid Power Filter to Compensate Four Wire Three Phase Systems", IEEE Trans. on Power Elects, Vol. 25,No.7,july 2010. 